\title{
SOSIALISASI KESEHATAN DAN PEMERIKSAAN ASAM URAT SERTA TEKANAN DARAH PADA LANSIA
}

\author{
Herlando Sinaga ${ }^{*} 1$; Andi Gita Novianti ${ }^{2}$; Fitri Kusuma Wardani ${ }^{3}$; Yunita Sari Kelibai ${ }^{4}$; \\ Desi Dona Sagrim ${ }^{5}$; Meliani Arinda Rahmawati ${ }^{6}$; Paulina Frensia Pano ${ }^{7}$; Sri Febrianty \\ Paranga $^{8}$; Umiati $^{9}$
}

\author{
1, 3, 4, 5, 6, 7, 8, 9 Prodi Analis Kesehatan; Universitas Sains dan Teknologi Jayapura \\ Jl. Raya Abepura-Sentani ; Jayapura ; Papua \\ ${ }_{2}^{2}$ Prodi Teknik Informatika; Universitas Sains dan Teknologi Jayapura \\ Jl. Raya Abepura-Sentani ; Jayapura ; Papua
}

\begin{abstract}
Abstrak
Lansia merupakan kelompok umur pada manusia yang telah memasuki tahapan akhir pada fase kehidupan. Kelompok yang dikategorikan lansia akan terjadi suatu proses penuaan. penyakit tersering yang diderita oleh lansia yang didominasi oleh penyakit tidak menular, penyakit kronik, dan degeneratif. Penyakit tersebut antara lain, hipertensi, arthritis, stroke, penyakit paru obstruktif kronik (PPOK), diabetes melitus, kanker, penyakit jantung koroner, batu ginjal, gagal jantung, dan gagal ginjal. Tujuan kegiatan pengabdian kepada masyarakat ini adalah untuk mengetahui kadar asam urat dan nilai tekanan darah pada lanjut usia di Kelurahan Koya Barat. Metode kegiatan melalui pemeriksaan kesehatan gratis serta sosialisasi kesehatan berdasarkan hasil pemeriksaan kesehatan yang didapatkan. Hasil pemeriksaan ditemukan, dari 30 lansia, 16 orang (53\%) mengalami asam urat tinggi, 13 orang (43\%) asam urat normal. Untuk pemeriksaan tekanan darah ditemukan 11 orang $(37 \%)$ mengalami hipertensi dan 19 orang (63\%) memiliki tekanan darah normal. Setelah dilakukan pemeriksaan kesehatan, hasil pemeriksaan disampaikan kepada lansia dan keluarga sekaligus diberikan sosialisasi agar lansia dapat menjaga kesehatannya dengan baik.
\end{abstract}

Kata kunci: asam urat ; tekanan darah ; lansia

\begin{abstract}
[HEALTH SOCIALIZATION AND TESTING OF URIC ACID AND BLOOD PRESSURE IN THE ELDERLY IN KOYA WEST JAYAPURA CITY] Elderly is an age group in humans who have entered the final stages of the life phase. Groups that are categorized as elderly will experience an aging process. The most common diseases suffered by the elderly are dominated by non-communicable diseases, chronic diseases, and degenerative diseases. These diseases include hypertension, arthritis, stroke, chronic obstructive pulmonary disease (COPD), diabetes mellitus, cancer, coronary heart disease, kidney stones, heart failure, and kidney failure. The purpose of this community service activity is to determine uric acid levels and blood pressure values in the elderly in Koya Barat Village. The method of activity is through free health checks and health socialization based on the results of the health checks obtained. The results of the examination found, from 30 elderly people, 16 people (53\%) had high uric acid and 13 people $(43 \%)$ had normal uric acid. For blood pressure examination, 11 people $(37 \%)$ had hypertension and 16 people $(53 \%)$ had normal blood pressure. After a health check is done, the results are notified to the elderly and their families as well as socialization so that the elderly can maintain their health properly.
\end{abstract}

Keywords: uric acid; blood pressure; elderly

\section{Pendahuluan}

Menurut World Health Organization (WHO), lansia adalah seorang yang telah memasuki usia 60 tahun ke atas. Lansia merupakan kelompok

\footnotetext{
*) Correspondence Author (Herlando Sinaga)

E-mail: herlandosinaga03@gmail.com
}

umur pada manusia yang telah memasuki tahapan akhir pada fase kehidupan. Kelompok yang dikategorikan lansia akan terjadi suatu proses penuaan (WHO, 2002). Berdasarkan data Riskesdas tahun 2018, penyakit yang terbanyak pada lansia adalah untuk penyakit tidak menular antara lain; hipertensi, masalah gigi, penyakit 
sendi, masalah mulut, diabetes mellitus, penyakit jantung dan stroke, dan penyakit menular antara lain seperti ISPA, diare, dan pneumonia. Prevalensi nasional penyakit sendi adalah 30,3\% (berdasarkan diagnosis tenaga kesehatan dan gejala). Papua menempati urutan ke empat setelah Aceh, Bengkulu dan Bali dalam hal prevalensi penderita penyakit sendi (Riskesdas, 2018). Asam urat merupakan hasil proses akhir dari metabolisme tubuh secara alami. Penyakit tersebut pada umumnya dapat mengganggu aktivitas harian penderita. Penderita tidur akan tanpa ada gejala, dan pagi harinya terasa sakit hingga tidak bisa berjalan (Suriana, 2014).

Prevalensi hipertensi di Indonesia yaitu 25,8\% dengan angka prevalensi untuk Sumatera 20,8\%, Jawa-Bali 24,3\%, dan kawasan Indonesia Timur 25,2 \% (Kemenkes RI, 2013). Hipertensi merupakan faktor risiko penyakit kardiovaskuler yang paling banyak ditemui di masyarakat dengan insidensi $10-15 \%$ pada orang dewasa. Kejadian hipertensi sering dikaitkan dengan bertambahnya usia karena meningkatnya jumlah penderita hipertensi seiring dengan peningkatan populasi lanjut usia (Siregar, 2003). Koya Barat merupakan salah satu kelurahan yang berada di Wilayah Distrik Muara Tami, Kota Jayapura. Kelurahan ini merupakan salah satu kelurahan yang terletak di bagian timur kota jayapura, dengan penduduk heterogen yang berjumlah 5.581 jiwa pada tahun 2021 (Pemprov Papua, 2021). Kunjungan pasien di Puskesmas Koya Barat tahun 2016 sebanyak 2458 pasien, jumlah pasien yang datang berkunjung dengan kartu sehat sebanyak 1080 orang, jumlah pasien kunjungan rawat jalan adalah 2105 , jumlah pasien rawat jalan yang berkunjung dengan usia $\geq 60$ tahun adalah sebanyak 102 orang, penyakit terbanyak yang dialami lansia yaitu asam urat, reumatik dan hipertensi (Puskesmas Koya Barat, 2018). Data Kelurahan Koya Barat pada tahun 2018 mencatat sebanyak 160 orang lansia tercatat tinggal dan mendiami Koya Barat (Kelurahan Koya Barat, 2018).

\section{Metode}

Metode yang digunakan dalam pengabdian ini meliputi pemeriksaan kesehatan dan sosialisasi kesehatan. Pemeriksaan kesehatan yang dilakukan terdiri dari pemeriksaan asam urat (Gambar 1) dengan menggunakan alat cek asam urat otomatis (Nesco Multicheck) dan pemeriksaan tekanan darah dengan menggunakan alat sphygmomanometer (Onemed). Hasil pemeriksaan tersebut digunakan sebagai dasar untuk memberikan sosialisasi kesehatan lansia terutama terkait penyakit asam urat kepada lansia beserta keluarga. Sosialisasi dilakukan dengan metode pembagian brosur dan penjelasan terkait penyakit asam urat dan dampaknya kepada lansia.

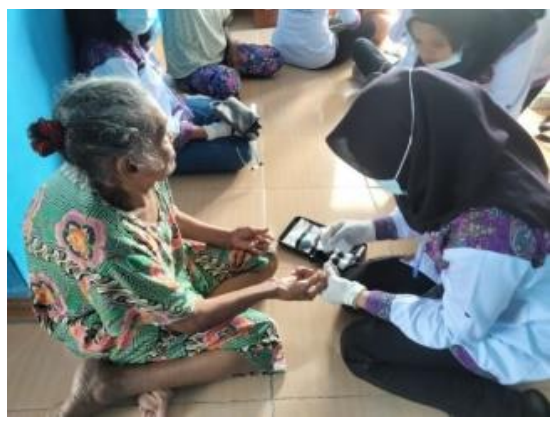

Gambar 1. Pemeriksaan Asam Urat pada masyarakat

\section{Hasil dan Pembahasan}

Dari hasil pemeriksaan asam urat dan tekanan darah pada Lansia di Koya Barat, diperoleh hasil:

Tabel 1 Hasil Pemeriksaan Asam Urat Pada Lansia

\begin{tabular}{lccccccc}
\hline \multirow{2}{*}{$\begin{array}{l}\text { Jenis } \\
\text { Kelamin }\end{array}$} & \multirow{2}{*}{ Jumlah } & \multicolumn{6}{c}{ Hasil Pemeriksaan } \\
\cline { 3 - 8 } & & $\mathbf{N}$ & $\%$ & $\mathbf{T}$ & $\%$ & $\mathbf{R}$ & $\%$ \\
\hline Laki-laki & 12 & 7 & 59 & 4 & 33 & 1 & 8 \\
Perempuan & 18 & 6 & 33 & 12 & 67 & - & - \\
\hline \multicolumn{1}{c}{ Total } & 30 & 13 & & 16 & & 1 & \\
\hline
\end{tabular}

$\mathrm{N}$ : Normal

$\mathrm{T}$ : Tinggi

$\mathrm{R}$ : Rendah

Interpretasi Asam Urat:

Pria : 3-7 mg/dL

Wanita : 2-6 mg/dL

Tabel 1 menunjukkan hasil pemeriksaan asam urat terhadap 30 sampel. Hasil asam urat laki-laki berjumlah 12 sampel terdiri dari 7 responden $(59 \%)$ asam urat normal, 4 responden $(33 \%)$ asam urat tinggi, dan 1 responden kadar asam urat rendah $(8 \%)$. Hasil pemeriksaan asam urat perempuan berjumlah 18 sampel terdiri dari 6 responden $(33 \%)$ asam urat normal, 12 responden $(67 \%)$ asam urat tinggi, dan tidak terdapat responden dengan asam urat rendah. 
Tabel 2 Hasil Pemeriksaan Tekanan Darah Pada Lansia

\begin{tabular}{lcrllllr}
\hline \multirow{2}{*}{$\begin{array}{l}\text { Jenis } \\
\text { Kelamin }\end{array}$} & \multirow{2}{*}{ Jumlah } & \multicolumn{7}{c}{ Hasil Pemeriksaan } \\
\cline { 3 - 8 } & & $\mathbf{N}$ & $\%$ & $\mathbf{T}$ & $\%$ & $\mathbf{R}$ & $\%$ \\
\hline Laki-laki & 12 & 5 & 42 & 6 & 50 & 1 & 8 \\
Perempuan & 18 & 11 & 61 & 5 & 28 & 2 & 11 \\
Total & 30 & 16 & & 11 & & 3 & \\
\hline
\end{tabular}

$\mathrm{N}$ : Normal

$\mathrm{T}$ : Tinggi

$\mathrm{R}:$ Rendah Lansia:

Interpretasi Pengukuran Tekanan Darah

Normal : Sistolik 130-140 mmHg / Diastolik 60$80 \mathrm{mmHg}$

Tinggi : Lebih besar dari 140/80 $\mathrm{mmHg}$

Rendah : Kurang dari 130/60 mmHg

Berdasarkan tabel 2 pada pemeriksaan tekanan darah terhadap 30 sampel. Hasil tekanan darah laki-laki berjumlah 12 responden terdiri dari 1 responden $(8 \%)$ tekanan darah rendah, 6 responden (50\%) tekanan darah tinggi, dan 5 responden (42\%) tekanan darah normal. Hasil tekanan darah pada responden berjenis kelamin perempuan berjumlah 18 responden terdiri dari 2 responden (11\%) tekanan darah rendah, 5 responden $(28 \%)$ tekanan darah tinggi, dan 11 responden $(61 \%)$ tekanan darah normal.

Pengabdian terkait pemeriksaan kadar asam urat dan tekanan darah pada lansia di Koya Barat sebanyak 30 responden. Target pengabdian ini yaitu seseorang yang telah berusia minimal 60 tahun (lanjut usia) dan bersedia menjadi responden. Menurut Putri (2017) pemeriksaan asam urat bertujuan untuk upaya deteksi penyakit seperti gout dan batu ginjal. Menurut Santoso (2010) pemeriksaan tekanan darah bertujuan untuk mengetahui kelainan pada jantung dan sistem peredaran darah serta menentukan suatu penyakit seperti stroke dan gangguan pada organ ginjal. Pemeriksaan kadar asam urat dan tekanan darah diperlukan untuk mengetahui kondisi kesehatan seseorang dan mendeteksi adanya gangguan kesehatan tertentu agar terhindar dari penyakit degeneratif lainnya.

Berdasarkan tabel 1 menunjukkan hasil pemeriksaan asam urat terhadap 30 sampel $(100 \%)$. Hasil asam urat laki-laki berjumlah 12 sampel terdiri dari 7 responden (59\%) asam urat normal, 4 responden (33\%) asam urat tinggi, dan $1(8 \%)$ responden dengan kadar asam urat rendah. Hasil pemeriksaan asam urat perempuan berjumlah 18 sampel terdiri dari 6 responden $(33 \%)$ asam urat normal, 12 responden $(67 \%)$ asam urat tinggi, dan tidak terdapat responden dengan asam urat rendah.

Berdasarkan tabel 1 diketahui bahwa perempuan lebih banyak mengalami asam urat tinggi dibanding laki-laki. Hal ini karena pada lanjut usia metabolisme tubuh akan mengalami penurunan, seperti produksi hormon esterogen yang berkurang pada perempuan mengakibatkan meningkatnya asam urat di dalam tubuh. Kadar asam urat didalam darah yaitu wanita 2-6 mg/dL dan pria 3-7 mg/dL. Menurut Nasir (2019) perempuan memiliki suatu hormon esterogen, namun seiring bertambahnya usia hormon ini mengalami penurunan fungsi sehingga meningkatkan resiko peningkatkan asam urat di dalam tubuh. Selain kerena dipengaruhi oleh hormon, tingginya hasil asam urat tersebut karenakan kurangnya perhatian terhadap asupan makanan yang mengandung purin seperti hati sapi, jeroan ikan, makanan kaleng terdapat bahan pengawet, sayuran hijau seperti kangkung dan bayam yang sering dikonsumsi oleh masyaraat pada umumnya. Salah satu cara untuk menurunkan asam urat yaitu dengan meminum air rebusan daun salam yang teruji mampu menurunkan asam urat seperti hasil penelitian dari Andriani dan Reny (2016) yang menemukan bahwa terdapat perbedaan kadar asam urat saat sebelum dan sesudah meminum air rebusan daun salam.

Hasil pemeriksaan pada tabel 1 ditunjang dengan pengabdian sebelumnya yang dilakukan di Arso Barat Kabupaten Keerom yang dilakukan oleh Prastyawati dan Ester (2020) yaitu yang mengalami kadar asam urat tinggi sebagian besar adalah lansia perempuan sebanyak 11 orang (38\%) dan pada lansia lakilaki tidak ada yang mengalami asam urat. Pada tabel 1 hasil pemeriksaan asam urat terdapat hasil dengan asam urat yang normal yaitu 7 pasien laki-laki (59\%) dan 6 pasien perempuan (33\%). Dalam pemeriksaan tersebut asam urat pada lansia dengan kadar yang tinggi disebabkan oleh makanan yang mengandung purin tinggi.

Berdasarkan tabel 2 pada pemeriksaan tekanan darah terhadap 30 sampel. Hasil tekanan darah laki-laki berjumlah 12 sampel terdiri dari 1 responden $(8 \%)$ tekanan darah rendah, 5 pasien (42\%) tekanan darah normal, dan 6 responden $(50 \%)$ tekanan darah tinggi. Hasil tekanan darah perempuan berjumlah 18 responden terdiri dari 2 responden $(11 \%)$ 
tekanan darah rendah, 11 responden $(61 \%)$ tekanan darah normal, dan 5 responden $(28 \%)$ tekanan darah tinggi. Hasil penelitian tersebut sejalan dengan penelitian sebelumya yang dilakukan oleh Oktafiani dan Rahmawati (2018) dengan hasil pemeriksaan tekanan darah sebagian besar yang mengalami hipertensi adalah lansia perempuan 55 orang $(57,3 \%)$ dan laki-laki 15 orang $(15,6 \%)$ lansia dengan tekanan darah normal 7 orang laki-laki $(7,3 \%)$ dan 19 orang perempuan $(19,8 \%)$.

Ada berbagai cara yang bisa dilakukan untuk upaya pencegahan yang baik untuk menghindari atau meminimalisir penyakit asam urat. Langkah pencegahan asam urat yang pertama adalah dengan rutin check up kesehatan terutama asam urat, kedua mengatur pola makan dengan memantau asupan makanan terutama yang mengandung purin. Ketiga mengatur pola hidup seperti melakukan kegiatan yang cukup dan sesuai, dimana lansia harus menghindari kegiatan yang berat dan beresiko tinggi terhadap kesehatannya. Keempat konsumsi buah yang mengandung vitamin dan mineral yang dibutuhkan bisa tercukupi dan membantu mengeluarkan racun didalam tubuh dan meningkatkan daya tahan tubuh.

Tekanan darah dipengaruhi oleh beberapa faktor yaitu umur, pola hidup, asupan makanan, dan faktor genetik. Pasien lansia dengan pola hidup yang masih kurang baik seperti minum alkohol, perokok aktif, konsumsi garam tinggi atau berlemak jenuh, serta kurangnya perhatian terhadap kesehatan tubuh sangatlah rentan mengidap tekanan darah tinggi. Akibatnya lansia mengalami gejala yang mengganggu aktifitas harian seperti sakit kepala berlebih, sesak nafas, nyeri dada dan leher terasa tegang. Hal tersebut sejalan dengan teori Dalimartha et al (2008) bahwa orang yang lebih tua cenderung memiliki tekanan darah yang tinggi dari orang yang berusia muda karena semakin bertambahnya usia maka tekanan darah semakin tinggi. Pada tabel 2 hasil tekanan darah dengan nilai tinggi cenderung dialami oleh perempuan. Hal tersebut sejalan dengan penelitian dari Kusumawaty dkk. (2016) bahwa hipertensi lebih banyak terjadi pada wanita.

\section{Simpulan dan Saran}

Hasil pemeriksaan menunjukkan bahwa terdapat cukup banyak lansia yang memiliki kadar asam urat dan tekanan darah yang melebihi batas normal, diharapkan perhatian lebih dari keluarga maupun dinas terkait kepada lansia agar dapat memperbaiki status kesehatan para lansia.

\section{Ucapan Terima Kasih}

Terima kasih disampaikan kepada para pihak yang sudah membantu hingga terlaksananya pengabdian ini, kepada kepala desa yang dengan antusias memberikan ijin hingga pengabdian ini dapat dilakukan dengan baik.

\section{Daftar Pustaka}

Andriani, Aida dan Reny Chaidir. Pengaruh Pemberian Air Rebusan Daun Salam (Syzygium polyanthum) Terhadap Penurunan Kadar Asam Urat. Jurnal Ipteks Terapan. 10 (2). 112-119.

Dalimartha S, Purnama BT, Sutarina N, Mahendra B, Darmawan R. (2008). Care Your Self Hypertension. Depok: Penebar Plus.

Kelurahan Koya Barat. 2018. Profil Kelurahan Koya Barat. https:// pemerintahkelurahan koyabarat.blogspot.com/2013/05/fasilitas -kesehatan-di-kelurahan-koya.Html?=1 . Diakses Pada Tanggal 22 Desember 2020.

Kemenkes RI. 2013. Riset Kesehatan Dasar: Riskesdas 2013. Jakarta: Kementerian Kesehatan RI.

Kusumawaty, Jujuk., Nur Hidayat, dan Eko Ginanjar. 2016. Hubungan Jenis Kelamin dengan Intensitas Hipertensi pada Lansia di Wilayah Kerja Puskesmas Lakbok Kabupaten Ciamis. Jurnal Mutiara Medika. 16 (2). 46-51. DOI: https://doi.org/10.18196/mmjkk.v16i2.44 50.

Nasir, M. (2017). Gambaran Asam Urat Pada Lansia Di Wilayah Kampung Selayar Kota Makassar. Jurnal Media Analis Kesehatan, 8(2), 78-82. https://doi.org/10.32382/mak.v8i2.842

Pemprov Papua. 2021. Data Luas Wilayah dan Jumlah Penduduk. https://www.papua.go.id/view-detailpage-205/data-luas-wilayah-dan-jumlahpenduduk.html. Diakses Pada Tanggal 12 November 2021.

Prastyawati, Rini., \& Ester Rampa. 2020. Sosialisasi Penyakit Gonore Dan 
Pemeriksaan Asam Urat Serta Tekanan Darah Pada Lansia Di Arso Barat Kabupaten Keerom. Jurnal Abdimas Dinamis, 1(2), 1-6.

Puskesmas Koya Barat. 2018. Data Jumlah Pasien dan Penyakit Tertinggi di Puskesmas Koya Barat Tahun 2018. Jayapura.

Putri, Nida'an Khofiyah Setiyo. 2017. Pengukuran Kadar Asam Urat Pada Perempuan Usia $\geq$ 40 Tahun. KTI. http://repo.stikesicmejbg.ac.id/303/1/Nida\%27an\%20Khofiyah \%20Setiyo\%20Putri\%20.pdf. Diakses pada tanggal 12 November 2021.

Riset Kesehatan Dasar 2018, Riset Kesehatan Dasar, Hasil Utama Riskesdas 2018. https://kesmas.kemkes.go.id/assets/uplo
ad/dir_519d41d8cd98f00/files/Hasilriskesdas-2018_1274.pdf. Diakses pada tanggal 11 November 2021.

Santoso, Djoko (2010). Membonsai Hipertensi. Surabaya: Jaring Pena.

Siregar, Tagor Gumanti Muda. 2003. Hipertensi Esensial. In: Sudoyo Dkk (Ed). Buku Ajar Ilmu Penyakit Dalam Jilid I Edisi IV. Jakarta: FKUI.

Suriana, N. 2014. Herbal Sakti Atasi Asam Urat. Depok: Mutiara Allamah Utama.

WHO. 2002. Definition of An Older or Elderly Person. http://www.who.in./healtinfo/survey/ageingdef nolder/en/. Diakses Pada Tanggal 22 Desember 2020. 